\title{
Spatial variability in the level of infestation of the leaves of horse chestnut by the horse chestnut leaf miner, Cameraria ohridella (Lepidoptera: Gracillariidae) and in the number of adult moths and parasitoids emerging from leaf litter in an urban environment
}

\author{
Michal KOPAČKA ${ }^{1,2}$ and RostisLAV ZEMEK ${ }^{2}$ \\ ${ }^{1}$ University of South Bohemia in České Budějovice, Faculty of Agriculture, Studentská 13, České Budějovice, Czech Republic; \\ e-mail: michalkopacka@seznam.cz \\ ${ }^{2}$ Biology Centre CAS, Institute of Entomology, Branišovská 31, České Budějovice, Czech Republic; e-mail: rosta@entu.cas.cz
}

Key words. Lepidoptera, Gracillariidae, Aesculus hippocastanum, leaf damage, population density, pest focus, parasitoids

\begin{abstract}
The horse chestnut leaf miner Cameraria ohridella Deschka \& Dimic (Lepidoptera: Gracillariidae) was first recorded in Europe near lake Ohrid in the former Yugoslav Republic of Macedonia in 1985 since when it has spread throughout the whole of Europe. The reasons for its spread are well documented. The aim of this study was to assess the population density of the first generation of $C$. ohridella at eight sites in the urban area of České Budějovice, Czech Republic in two consecutive years. The density was estimated visually in terms of the damage done to horse chestnut leaves by $C$. ohridella larvae at each site during the vegetative season. The results revealed high variability in the mean percentage of the leaf area damaged ranging from $1.43 \%$ to $31.00 \%$ and from $0.26 \%$ to $23.40 \%$ in 2012 and 2013 , respectively. The effect of site, year and interaction between these two factors were statistically highly significant. Spatial analysis revealed no autocorrelation in damage among sites indicating that the distribution of $C$. ohridella is random and not affected by the level of infestation at neighbouring sites. In autumn, samples of leaves were collected and the mortality of diapausing pupae of $C$. ohridella determined. It ranged from $12.50 \%$ to $25.82 \%$ and from $10.31 \%$ to $22.35 \%$ in 2012 and 2013 , respectively. There was no significant effect of site and year and their interaction on pupal mortality. The leaf samples were then weighed and put into photo-eclectors, which were placed outdoors. Numbers of adults of $C$. ohridella and hymenopteran parasitoids that emerged in spring were recorded daily. There were statistically significant associations of the total number of adults that emerged from samples in spring with both site and year as well as their interaction. The number of moths that emerged was positively correlated with the damage done by the first generation of $C$. ohridella the previous year. Similarly, the total number of parasitoids that emerged was correlated with the number of moths that emerged. The implications of these findings for the optimization of $C$. ohridella control are discussed.
\end{abstract}

\section{INTRODUCTION}

The horse chestnut leaf miner, Cameraria ohridella Deschka \& Dimic (Lepidoptera: Gracillariidae), was recorded at Lake Ohrid in the former Yugoslav Republic of Macedonia in 1985 for the first time but it is unknown whether it is the place from which this species subsequently spread (Deschka \& Dimic, 1986; Grabenweger \& Grill, 2000; Valade et al., 2009) through Austria and then throughout Europe and Asia Minor (Puchberger, 1995; Guichard \& Augustin, 2002; Kindl et al., 2002; Cebeci \& Acer, 2007). It arrived in the Czech Republic in 1993 (Liška, 1997).

Main host plant of C. ohridella is the horse chestnut tree, Aesculus hippocastanum L., and occasionally sycamore, Acer pseudoplatanus L., mostly when growing in the immediate vicinity of infested horse chestnut trees. However, larval mortality during the first two instars is more than $70 \%$ on $A$. pseudoplatanus. Cameraria ohridella lays its eggs on leaves of many other species of trees, e.g. Aesculus $x$ carnea Hayne, Acer platanoides L. and Fraxinus excelsior L. Leaves of these species, however, contain saponins, which prevent $C$. ohridella from completing its development (Ferracini et al., 2010; Péré et al., 2010). As well as the horse chestnut leaf miner its parasitoids also overwinter in fallen leaves (Samek, 2003). In spring, the adult females of the leaf miner emerge from overwintered pupae and lay 32-82 eggs (Girardoz et al., 2007b) in the upper epidermis of the leaves of horse chestnut trees. Horse chestnut leaf miner is a multivoltine species, which usually has three overlapping generations in the middle of Europe (Skuhravý, 1999; Santi et al., 2000). The number of eggs is independent of generation (Girardoz et al., 2007b). Some of the pupae in each generation enter diapause. The proportion entering diapause increases with increase in the damage to the leaves of horse chestnut (Samek, 2003). 
Diapausing pupae are larger and heavier and contain more nutrients for sustaining their much longer non-feeding period than the pupae in the same generation that immediately metamorphose into adults (Weyda et al., 2015).

Besides aesthetic damage, infestation by $C$. ohridella affects the photosynthetic activity of $A$. hippocastanum (Nardini et al., 2004), causes premature leaf fall and significantly shortens foliage lifespan (Freise \& Heitland, 2001). This, in turn, negatively affects the reproduction of trees (Salleo et al., 2003; Thalmann et al., 2003).

No specific parasitoid of $C$. ohridella has been recorded in Europe, even in areas where they are most likely to occur. Its parasitoid complex (Hymenoptera) includes about 20 species. The most dominant species are Minotetrastichus frontalis (Nees) and Pediobius saulius (Walker) (Hymenoptera: Eulophidae) (Volter \& Kenis, 2006; Grabenweger et al., 2007; Cebeci et al., 2011). These two species are also the most abundant parasitoids recorded in the Czech Republic (Zemek et al., 2006). Parasitoids do not attack eggs and first instar larvae of $C$. ohridella but usually prefer attacking the $4^{\text {th }}-6^{\text {th }}$ larval instars (Grabenweger, 2003). In spring the parasitoids are poorly synchronized with $C$. ohridella and as a consequence do not regulate the abundance of this pest (Grabenweger, 2004; Grabenweger et al., 2007). The mortality of first generation of the horse chestnut leaf miner is very low compared to that of other taxonomically closely related mining moths (Zemek et al., 2006; Grabenweger, 2003).

The control of $C$. ohridella during the vegetative season is very difficult and expensive and therefore usually not implemented across the whole city. There are several options, pheromone traps (Svatoš et al., 1999, 2009; Grodner et al., 2008; Sukovata et al., 2011), spraying trees with pesticides (Perju et al., 2004; Kuldová et al., 2015) and injection of trees with insecticides (Měsić et al., 2008; Kobza et al., 2011).

Despite the fact that less than $15 \%$ of overwintering pupae of $C$. ohridella survive the winter in fallen leaves, mechanical removal at the end of a year of infested leaves with diapausing pupae of $C$. ohridella is absolutely necessary to control the first generation of horse chestnut leaf miner the following spring (Girardoz et al., 2007b). As leaf fall occurs gradually over a long period of time leaf removal is time-consuming and technically challenging (Kehrli \& Bacher, 2003; Pavan et al., 2003). The collected leaves can be burned or better, covered by soil (Kehrli \& Bacher, 2004), composted (Kopačka, 2011) or put into special barrels allowing the release of smaller parasitoids while trapping adult moths inside (Kehrli et al., 2005). The pupae that fall out of their cocoons during the handling of leaves are likely to be eaten by predators or saprophages (Girardoz et al., 2007b) or might be infected by soilborn entomopathogenic fungi, which frequently occur in the vicinity of A. hippocastanum trees (Prenerová et al., 2009). These fungi are proposed as a suitable biocontrol agent against $C$. ohridella (Zemek et al., 2006). Spontaneous infections of $C$. ohridella pupae by entomopathogenic fungi are recorded (Samek et al., 2006; Zemek et al., 2007;
Schemmer et al., 2016) and some fungal strains are effective (Richter et al., 2007a, b; Zemek et al., 2012; Prenerová et al., 2013; Schemmer et al., 2016).

To optimize the control of the horse chestnut leaf miner in cities we need to understand its spatio-temporal population dynamics. Despite the large number of papers on this species only a few studies deal with spatial patterns of C. ohridella in an urban environment. The most detailed study is that of Gilbert et al. (2003). The authors analyzed data on the infestation levels in Bern (Switzerland) in 1998 and 2000 and Brussels (Belgium) in 2001 estimated during the period of the second to third generation visually as the number of mines counted within a period of $30 \mathrm{~s}$ on one tree per site or as percentage of damaged foliage (Gilbert \& Gregoire, 2003). In the Brussels survey C. ohridella abundance was also measured using pheromone traps. Several explanatory variables, including distance to the nearest site with chestnut trees and information on whether the leaf litter was removed or not, were used in a step-wise multiple regression analysis and the decrease in infestation level as a function of distance from potential population reservoirs tested. Their results indicate a strong spatial dependence of infestation level up to a distance of about 1 and $2 \mathrm{~km}$ in Bern and Brussels, respectively, and quantitatively demonstrate that the amount of leaf litter left at a site is the main factor explaining the variability in the level infestation by C. ohridella. In contrast, studies carried out in Poland indicate that the mean distance between horse chestnut trees has a significant effect on the infestation level only in the third generation of $C$. ohridella larvae and only in small towns (Baraniak et al., 2004) while in large towns it has no effect (Baraniak et al., 2005). In both studies the correlation between infestation and distance to uncontrolled sites, i.e. sites without litter removal, were insignificant.

The aim of the present study was to determine the intra-urban variation of $C$. ohridella population density in a medium-sized city in Central Europe in two consecutive years during the period when the first generation completes its development. Spatial analysis of data was conducted to reveal if there is any gradient between sites. In addition, we recorded $C$. ohridella parasitoids emerging in spring from fallen leaves and determined whether these counts are correlated with the infestation level in spring.

\section{MATERIALS AND METHODS}

\section{Study sites}

The study area was the town of České Budějovice, South Bohemia $\left(49^{\circ} \mathrm{N}\right.$, Czech Republic). The city has a population of around 100,000 and a cadastral area of $56 \mathrm{~km}^{2}$. The town is surrounded by agricultural fields and forests. Total number of horse chestnut trees in the town was estimated to be 534 (Kopačka, 2011). For the purpose of the present study the city area was divided into eight more or less isolated sites where most of horse chestnut trees in the city occurred (Fig. 1, Table 1). These sites differed in the percentage of green area, number of trees and their age as well as possible pollution from traffic and industrial sources and in intensity of management. While the most intensive management was in the "City centre" where the lawn is mowed more than four times per year and leaf litter carefully removed in autumn, there 


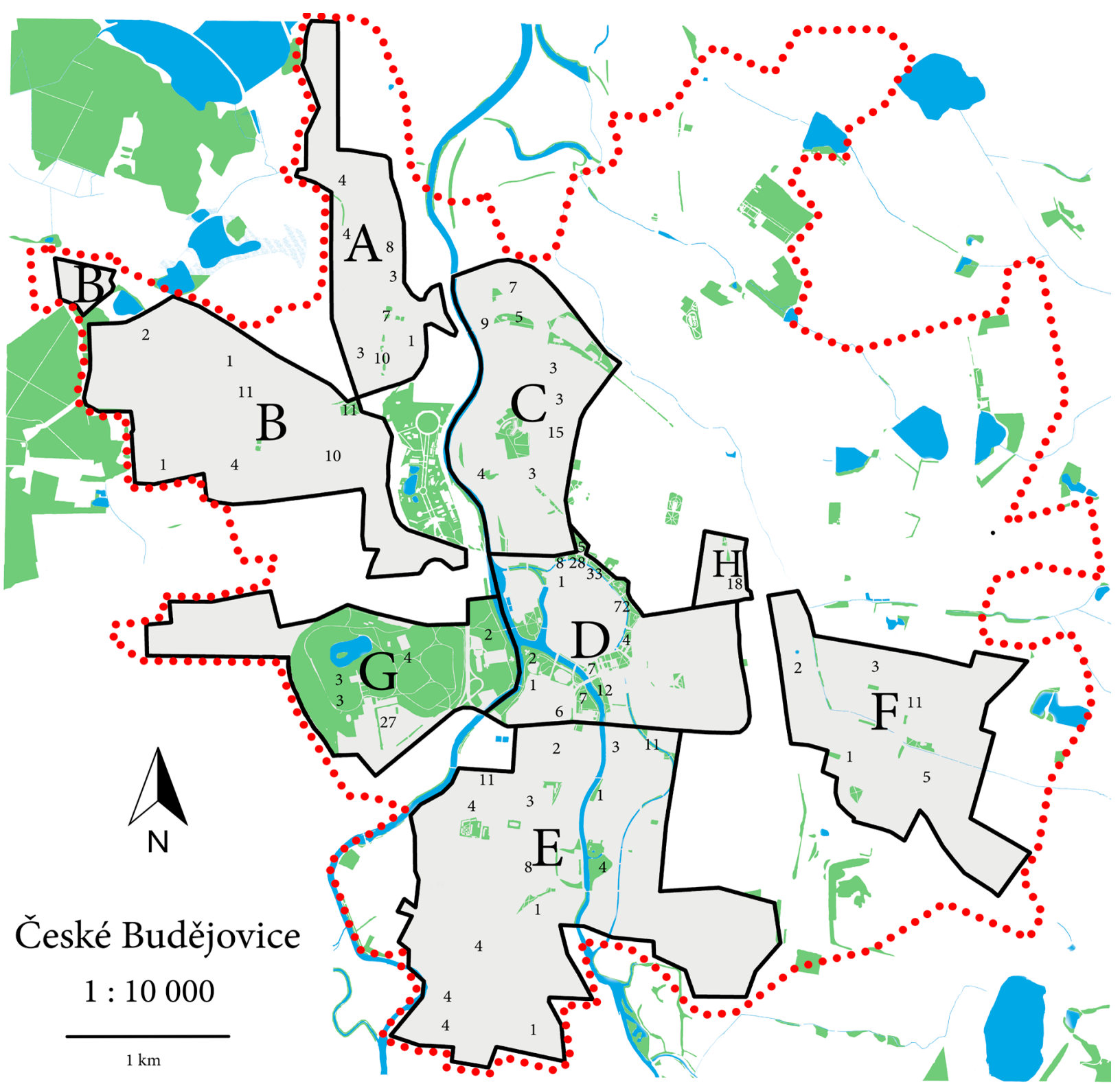

Fig. 1. Map of České Budějovice. Capital letters indicate sites studied and numbers the number of horse chestnut trees at a particular location. Green and blue colours indicate parks or forests and water (ponds, rivers), respectively.

was no management in "Nádražní Street", in particular the leaf litter was not removed (Table 1). The average cadastral area of a study site was 139.38 ha $(\mathrm{SEM}=28.17, \mathrm{n}=8)$ and the average green public open space of a site was 30.38 ha $(\mathrm{SEM}=6.90, \mathrm{n}$ $=8$ ).

All A. hippocastanum trees at each site were counted and their age was estimated using the method proposed by Jura (2001). The

Table 1. Characteristics of the sites studied.

\begin{tabular}{|c|c|c|c|c|c|c|c|c|c|}
\hline \multicolumn{2}{|l|}{ Sampling site } & \multirow{2}{*}{$\begin{array}{l}\text { Cadastral } \\
\text { area } \\
\text { [ha] }\end{array}$} & \multirow{2}{*}{$\begin{array}{c}\text { Green } \\
\text { public } \\
\text { open } \\
\text { space } \\
\text { [ha] }\end{array}$} & \multirow{2}{*}{$\begin{array}{l}\text { Geometric centre of site } \\
\text { [GPS coordinates] }\end{array}$} & \multirow{2}{*}{$\begin{array}{l}\text { Number } \\
\text { of horse } \\
\text { chestnut } \\
\text { trees }\end{array}$} & \multirow{2}{*}{$\begin{array}{c}\text { Mean } \\
( \pm \text { SEM }) \\
\text { age } \\
\text { of trees } \\
\text { [year] }\end{array}$} & \multirow{2}{*}{$\begin{array}{l}\text { Urban } \\
\text { greenery } \\
\text { type }\end{array}$} & \multirow{2}{*}{$\begin{array}{l}\text { Mowing } \\
\text { [times] }\end{array}$} & \multirow{2}{*}{$\begin{array}{l}\text { Litter } \\
\text { removal } \\
\text { in } \\
\text { autumn }\end{array}$} \\
\hline Description & $\overline{\text { Label }}$ & & & & & & & & \\
\hline Vltava estate & A & 92 & 34 & $48.9962106 \mathrm{~N}, 14.4519647 \mathrm{E}$ & 40 & $41.78 \pm 3.48$ & Park & $3-4$ & Yes \\
\hline Máj and Šumava estate & B & 183 & 58 & $48.9854603 \mathrm{~N}, 14.4417294 \mathrm{E}$ & 40 & $39.02 \pm 3.19$ & Park & $3-4$ & Yes \\
\hline Pražské předměstí & C & 124 & 37 & $48.9860569 \mathrm{~N}, 14.4674681 \mathrm{E}$ & 49 & $53.74 \pm 2.75$ & Park & $3-4$ & Yes \\
\hline City centre & $\mathrm{D}$ & 133 & 12 & $48.9744136 \mathrm{~N}, 14.4770594 \mathrm{E}$ & 186 & $78.99 \pm 1.85 \mathrm{P}$ & ark, riverbank & $k>4$ & Yes \\
\hline Rožnov & $E$ & 294 & 32 & $48.9601436 \mathrm{~N}, 14.4763944 \mathrm{E}$ & 61 & $74.49 \pm 4.42 \mathrm{P}$ & ark, riverbank & k $3-4$ & Yes \\
\hline Suché Vrbné and Nové Vráto & $\mathrm{F}$ & 146 & 17 & $48.9693503 \mathrm{~N}, 14.5026531 \mathrm{E}$ & 22 & $61.77 \pm 4.20$ & Park & $3-4$ & Yes \\
\hline Stromovka and Sokolský ostrov & $G$ & 130 & 52 & $48.9695822 \mathrm{~N}, 14.4528069 \mathrm{E}$ & 39 & $60.35 \pm 2.84$ & Park & $3-4$ & Yes \\
\hline Nádražní street & $\mathrm{H}$ & 13 & 1 & $48.9779942 \mathrm{~N}, 14.4866511 \mathrm{E}$ & 18 & $77.74 \pm 3.02$ & Alley & 0 & No \\
\hline
\end{tabular}


a)

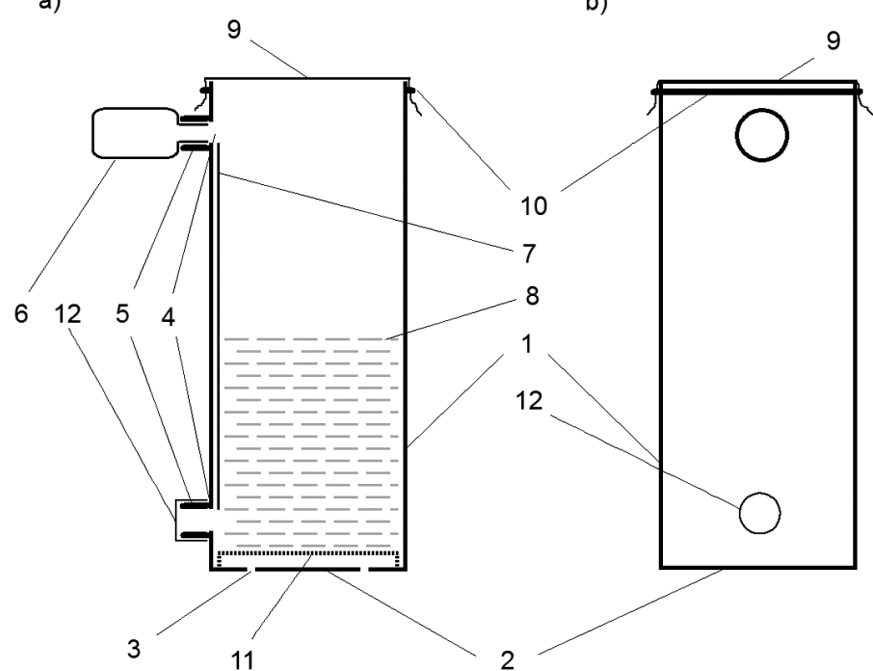

c)

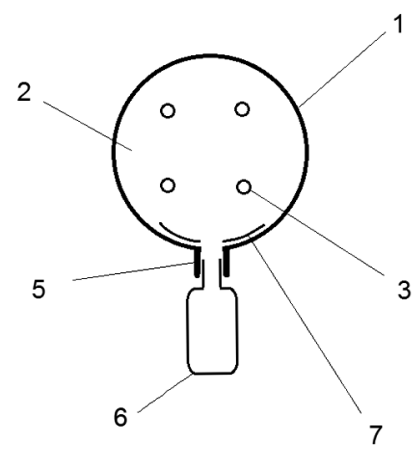

Fig. 2. The structure of a photo-eclector: $\mathrm{a}$ - cross-section, $\mathrm{b}$ - side view, $\mathrm{c}$ - top view; individual parts of photo-eclector: 1 - main container (metal, height $78.0 \mathrm{~cm}$, diameter $31.5 \mathrm{~cm}$ ), 2 - bottom, 3 - superimposed synthetic fabrics, 4 - exit aperture, 5 - attachments for collecting bottle (plastic foam), 6 - collecting bottle (polyethylenne, $250 \mathrm{ml}$ ), 7 - roughening on the inner side of the cylinder (sawdust), 8 - leaf litter, 9 - lightproof fabric, 10 - elastic tape, 11 - wire drainage grate, 12 - plug hole.

method is based on a measurement of trunk perimeter and tree age is calculated using the following equation:

$A=\frac{5}{\pi \cdot w_{l p}} \cdot p_{1.3}$

where $A$ is tree age, $p_{13}$ is trunk perimeter at $1.3 \mathrm{~m}$ above the ground and $w_{l p}$ is mean width of growth ring for a particular species, which for A. hippocastanum is 3.52 (Jura, 2001). This survey showed that the average number of horse chestnut trees was $56.88(\mathrm{SEM}=19.07, \mathrm{n}=8)$ with an average age of 66.26 years $(\mathrm{SEM}=1.32, \mathrm{n}=8)$. The study was carried out between 2012 and 2014.

\section{Population density of the first generation of $C$. ohridella}

Thirty compound leaves were randomly collected from horse chestnut branches at heights up to $2.5 \mathrm{~m}$ above the ground. Trees sampled were selected evenly across the whole site. Only one leaf per tree was collected except for two sites with less than 30 trees where up to two leaves from a single tree were collected. Sampling was done on 19 July 2012 and 14 July 2013, i.e. when the first generation of horse chestnut leaf miner was hatching. The population density of $C$. ohridella was assessed as a percentage of the leaf area damaged by the larvae. The visual method proposed by Gilbert \& Gregoire (2003) was used to estimate leaf damage.

\section{Mortality of diapausing pupae of $\boldsymbol{C}$. ohridella in autumn and emergence of $\boldsymbol{C}$. ohridella adults and hymenopteran parasitoids from leaf samples after overwintering}

About 600-800 leaves (approx. three kilograms fresh weight) from A. hippocastanum branches up to $2.5 \mathrm{~m}$ above the ground were collected at each site evenly to represent its whole area during a period from 7 to 13 November 2012 and from 26 October to 1 November 2013. At that period most leaves were yellow/ brown and had started to fall. All samples were put into large permeable sacks $(55 \times 120 \mathrm{~cm})$ and transported to the laboratory where the water content of the leaves and mortality of diapausing pupae were determined. For the water content measurement, three subsamples from each site were weighed, dried in a dessicating cabinet at a temperature of $80^{\circ} \mathrm{C}$ until constant weight and the water content determined based on the weight loss. Mortality of pupae was estimated for three subsamples per site, each
60 grams in dry weight (about 30 leaves), which were inspected for pupal chambers, the cocoons were dissected and pupae were checked to determine if they were alive or dead.

Based on the water content results, leaf samples consisting of an equivalent of 125 and 182 grams of dry matter in 2012 and 2013, respectively, were placed individually into forty photoeclectors (Fig. 2) developed by Doležal et al. (2012) giving five replications per study site. The photo-eclectors were placed in the shade outdoors. Temperature was measured both outside and inside the photo-eclectors (one per site) using a digital thermometer. The minimum and maximum temperatures were recorded every third day until the end of the study, which was the end of June the following year. Since the beginning of early spring, the plastic bottles in the photo-eclectors were checked daily. If insects were trapped in the bottle, the bottle was replaced and caught specimens were killed in a freezer. After $24 \mathrm{~h}$ the dead specimens were transferred to labelled plastic Petri dishes (diam. $6 \mathrm{~cm}$ ) and stored in the freezer until specimens were determined.

\section{Data presentation and statistical analysis}

All data were stored in a database using Microsoft Access 2010. Leaf damage data were analyzed using two-way ANOVA with site location and year as main factors. Since dependent variable data are not normally distributed, the arcsine square-root transformation (Sokal \& Rohlf, 1969; Zar, 1999) was used to normalize the percentage data before statistical analysis.

Logistic regression was applied to the data on mortality of diapausing pupae and the lower and upper limits of the $95 \%$ confidence interval for a percentage was calculated according to the method described by Newcombe (1998). The numbers of adults of $C$. ohridella and hymenopteran parasitoids that emerged in spring were recalculated in terms of the numbers per 1000 grams of dry leaves and the values log-transformed. Multivariate Analysis of Variance (MANOVA) (Zar, 1999) was used to analyse the data. The relationship between the total number of parasitoids and C. ohridella adults that emerged was described by linear regression. A Spearman correlation analysis (Siegel \& Castellan, 1988) was used to test if any relationship exists between the leaf damage by $C$. ohridella during the first generation and the number of adult moths that emerged from leaf samples after overwintering. 

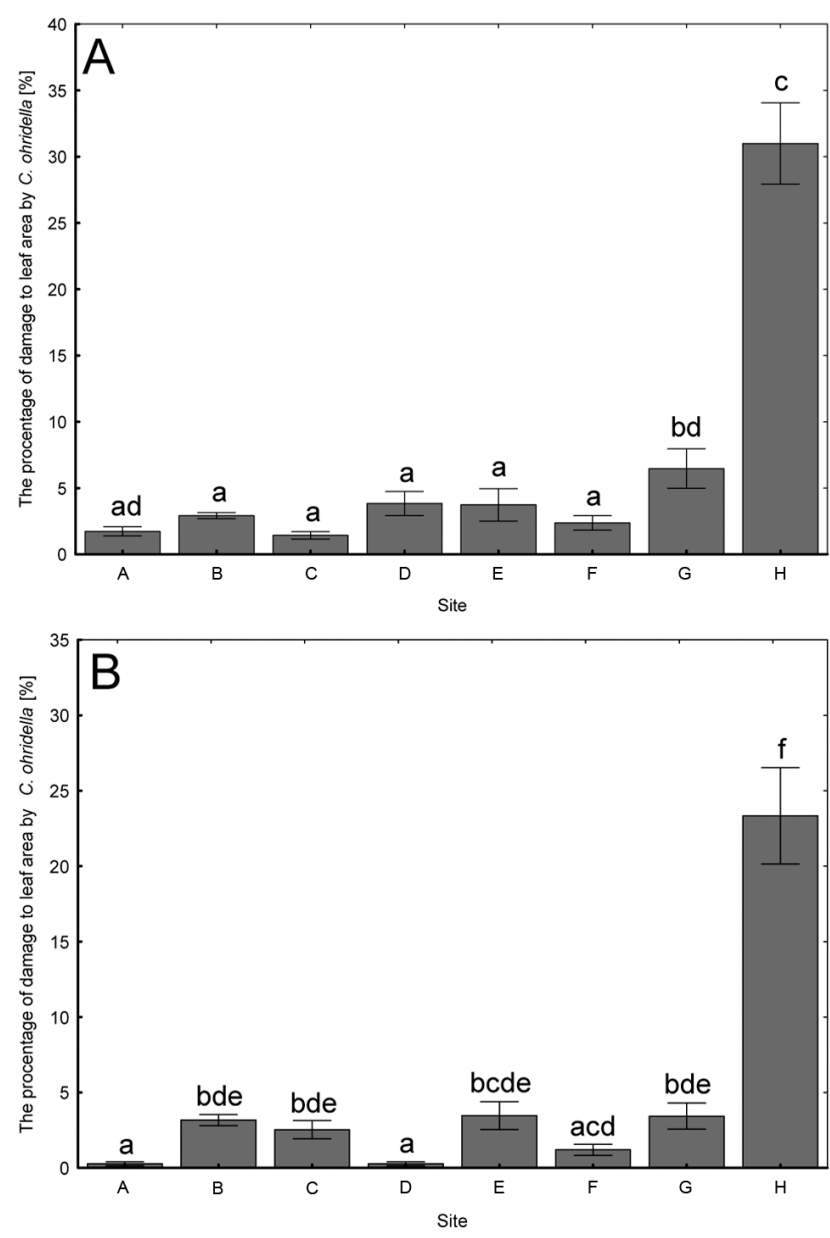

Fig. 3. Percentage of leaf area damaged by the first generation of Cameraria ohridella (mean \pm SEM, $n=30$ ) in $2012(A)$ and 2013 (B). Different letters above bars indicate significant differences (Tukey's test; $p<0.05$ ).

Statistical evaluation of the spatial autocorrelation among sites in terms of leaf damage and the numbers of $C$. ohridella and hymenopteran parasitoids that emerged in spring was carried out using Moran's index calculated in Microsoft Excel 2010 (Chen, 2013). For this purpose distances between the geometric centres of sites were calculated using the GPS coordinates in Table 1.

All computations and graphical presentation of results, except the spatial analysis, were done using STATISTICA 12 (StatSoft). Statistical tests use two-tailed probabilities.

\section{RESULTS}

\section{Population density of the first generation of C. ohridella}

The mean percentage of damaged leaf area ranged from $1.43 \%$ to $31.00 \%$ and from $0.26 \%$ to $23.40 \%$ in 2012 and 2013 , respectively. The lowest value was recorded in 2013 and highest in 2012 (Fig. 3). The overall mean damage was higher in $2012(5.84 \% \mathrm{SEM}=0.62, \mathrm{n}=240)$ than in 2013 $(4.32 \%, \mathrm{SEM}=0.52, \mathrm{n}=240)$. The highest infestation was recorded at "Nádražní Street" where the leaf damage of single leaves sometimes exceeded $50 \%$. The ANOVA revealed that the association with both site and year were statistically highly significant $\left(\mathrm{F}_{7,584}=98.984, \mathrm{P}<0.0001\right.$, and $\mathrm{F}_{1,584}=23.924, \mathrm{P}<0.0001$, respectively). The interac-
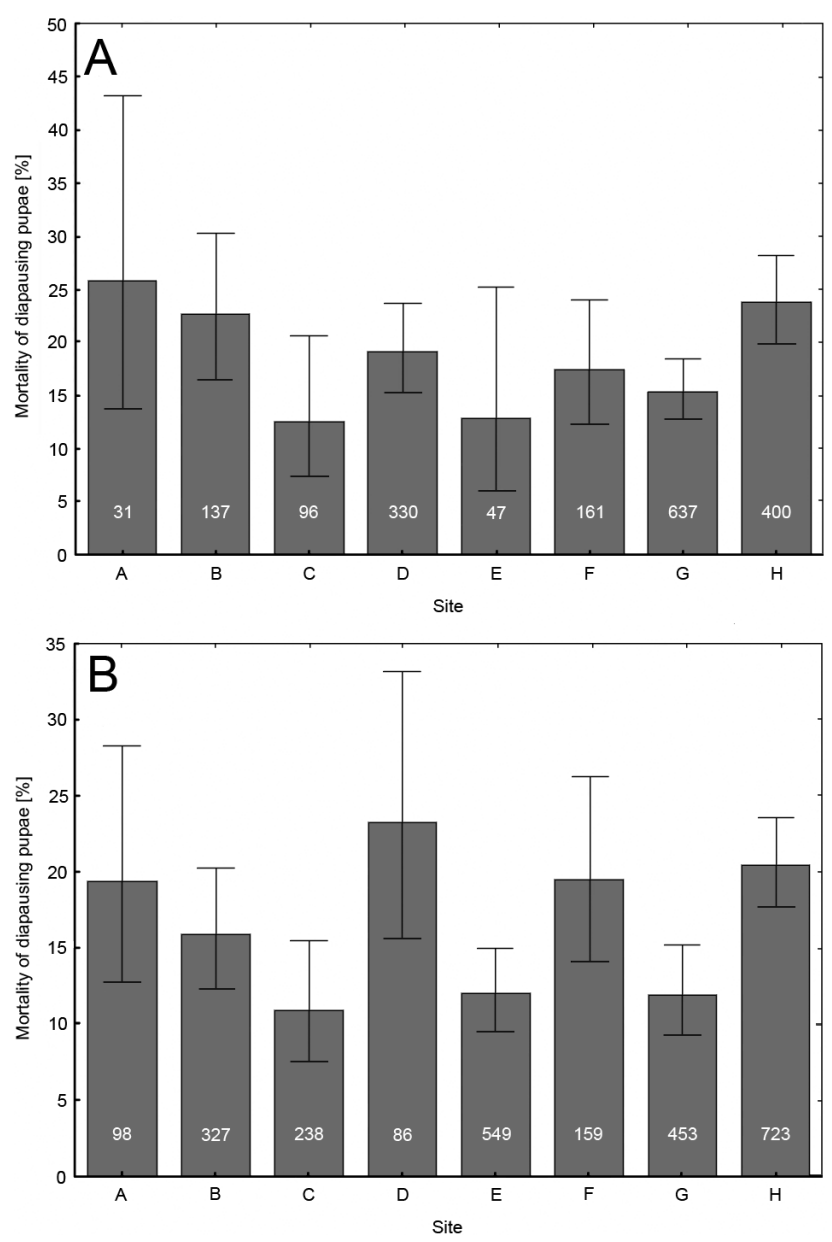

Fig. 4. Percentage of dead diapausing pupae of Cameraria ohridella at the end of vegetative season in 2012 (A) and 2013 (B). Vertical lines indicate $95 \%$ confidence intervals; numbers in bars indicate the total number of pupae checked per site.

tion between these two factors was also highly significant $\left(\mathrm{F}_{7,584}=4.119, \mathrm{P}=0.0002\right)$.

Spatial analysis of the damage inflicted by $C$. ohridella during the vegetative season revealed a zero spatial autocorrelation (Moran's I $=-0.2215, \mathrm{P}>0.05$ ). This indicates that the population density of $C$. ohridella at a particular site is not significantly affected by the density at neighbouring sites.

\section{Mortality of diapausing pupae of C. ohridella recorded in autumn}

Mortality of C. ohridella pupae at individual sites ranged between $12.50 \%$ and $25.81 \%$ and between $10.92 \%$ and $23.26 \%$ in 2012 and 2013, respectively (Fig. 4). The overall mortality in 2012 was $18.54 \%(95 \% \mathrm{CI}=16.83-20.38$; $\mathrm{n}=1839)$ and slightly lower in 2013 at $15.80 \%(95 \%$ CI $=14.46-17.24 ; \mathrm{n}=2633)$. The logistic regression revealed that the association of mortality with site was statistically highly significant (Wald $\chi^{2}=39.848$, df $=7, \mathrm{P}<0.0001$ ) but that with year was not significant (Wald $\chi^{2}=1.449$, df $=1, \mathrm{P}=0.2287)$. The interaction between site and year factors was also not significant (Wald $\chi^{2}=5.047, \mathrm{df}=7, \mathrm{P}$ $=0.6542)$. 

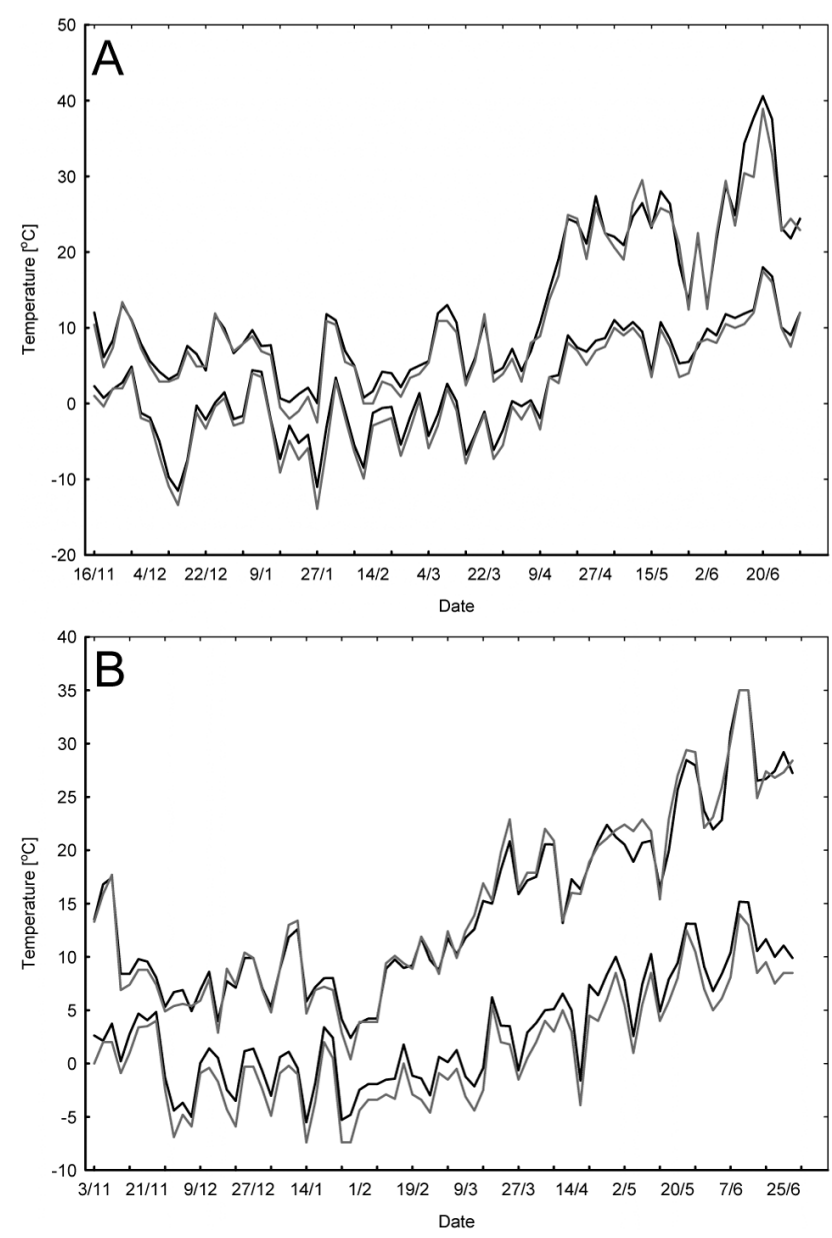

Fig. 5. Course of daily minimum and maximum temperatures inside (black lines) and outside (grey lines) the photo-eclectors during two experimental periods. A: 2012-2013, B: 2013-2014.

\section{Emergence of $\boldsymbol{C}$. ohridella adults and hymenopteran parasitoids from leaf samples after overwintering}

The outdoor air temperature during the first and the second experimental periods ranged from $-8.2^{\circ} \mathrm{C}$ to $28.2^{\circ} \mathrm{C}$ and from $-3.5^{\circ} \mathrm{C}$ to $24.5^{\circ} \mathrm{C}$, respectively, with means of $6.58^{\circ} \mathrm{C}(\mathrm{SEM}=0.94, \mathrm{n}=77)$ and $8.07^{\circ} \mathrm{C}(\mathrm{SEM}=0.74$, $\mathrm{n}=80$ ), respectively. This indicates a rather mild winter in the second year of the study (Fig. 5). The temperature measured inside photo-eclectors was very similar to that described above, ranging from $-5.5^{\circ} \mathrm{C}$ to $29.29^{\circ} \mathrm{C}$ in the first and $-1.2^{\circ} \mathrm{C}$ to $25.22^{\circ} \mathrm{C}$ in the second year of the study. The mean temperatures were $9.64^{\circ} \mathrm{C}(\mathrm{SEM}=1.67, \mathrm{n}=77)$ and $8.88^{\circ} \mathrm{C}(\mathrm{SEM}=0.72, \mathrm{n}=80)$, respectively.

The dynamics of the emergence of C. ohridella (Fig. 6) and its parasitoids (Fig. 7) reveal large differences among samples collected at the various sites. It also shows that in 2014 the peak of emergence was about two weeks later than in 2013. The total number of $C$. ohridella that emerged per kilogram of dry leaves of $A$. hippocastanum ranged from 191 to 4118 and from 171 to 5398 in 2013 and 2014, respectively (Fig. 8). The mean number was 1417 $(\mathrm{SEM}=170.86, \mathrm{n}=8)$ in 2013 and $1809(\mathrm{SEM}=243.37, \mathrm{n}$ $=8$ ) in 2014. The numbers of parasitoids that emerged per kilogram of leaves (Fig. 9) ranged from 0 to 807 and from
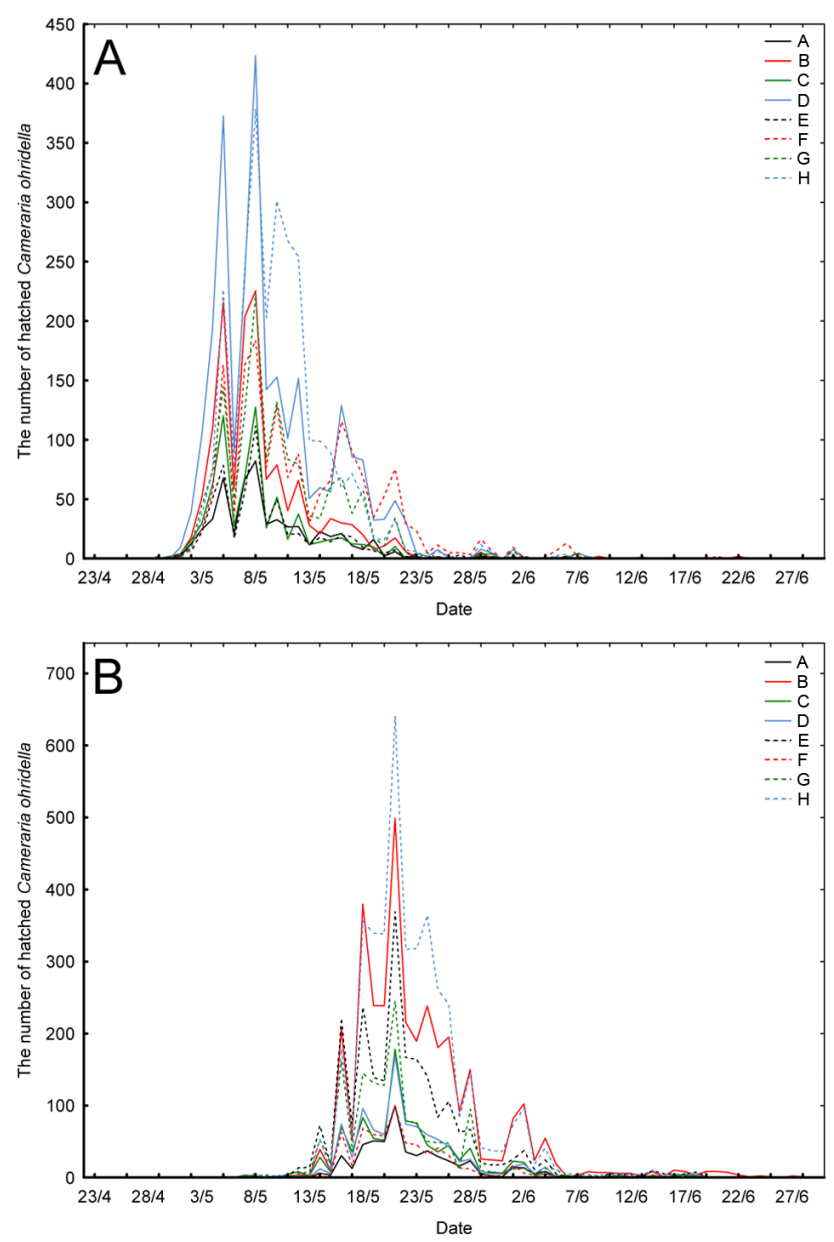

Fig. 6. Dynamics of the spring emergence of Cameraria ohridella (mean daily number hatched) in 2013 (A) and 2014 (B) per 1000 grams of dry leaves collected at each of the sites $(A-H)$.

5 to 936 in 2013 and 2014, respectively. The mean was 272 $(\mathrm{SEM}=33.51, \mathrm{n}=8)$ in 2013 and $237(\mathrm{SEM}=38.38, \mathrm{n}$ $=8)$ in 2014. MANOVA revealed a highly significant association with both sites (Wilk's $\lambda=0.2872, \mathrm{~F}_{14,126}=7.794$, $\mathrm{P}<0.0001$ ) and year (Wilk's $\lambda=0.7039, \mathrm{~F}_{2.63}=13.251, \mathrm{P}$ $<0.0001)$. The interaction between site and year was also highly significant (Wilk's $\lambda=0.4667, \mathrm{~F}_{14,126}=4.176, \mathrm{P}<$ $0.0001)$.

The numbers of individuals of the parasitoid complex were positively correlated with the number of adults of $C$. ohridella that emerged in spring $(\mathrm{r}=0.6857, \mathrm{P}=0.0001$, $\mathrm{n}=80$, Fig. 10). The relationship is described by the equation $y=69.68572+0.11577 x$ where $y$ is the number of parasitoids and $x$ the number of adult $C$. ohridella. There was also a highly significant positive correlation between the number of $C$. ohridella adults in spring and leaf area damaged the previous year when the first generation hatched $\left(\mathrm{r}_{\mathrm{s}}\right.$ $=0.6623, \mathrm{n}=16, \mathrm{P}=0.0051$ ).

Spatial analysis of number of horse chestnut leaf miners that emerged confirmed zero spatial autocorrelation among the sites studied (Moran's I $=-0.1732, \mathrm{P}>0.05$ ). Similar results were obtained for spatial analysis of parasitoid emergence (Moran's $\mathrm{I}=-0.2080, \mathrm{P}>0.05$ ). These results indicate that the numbers of diapausing pupae and parasitoids in leaf samples was not associated with that at neigh- 

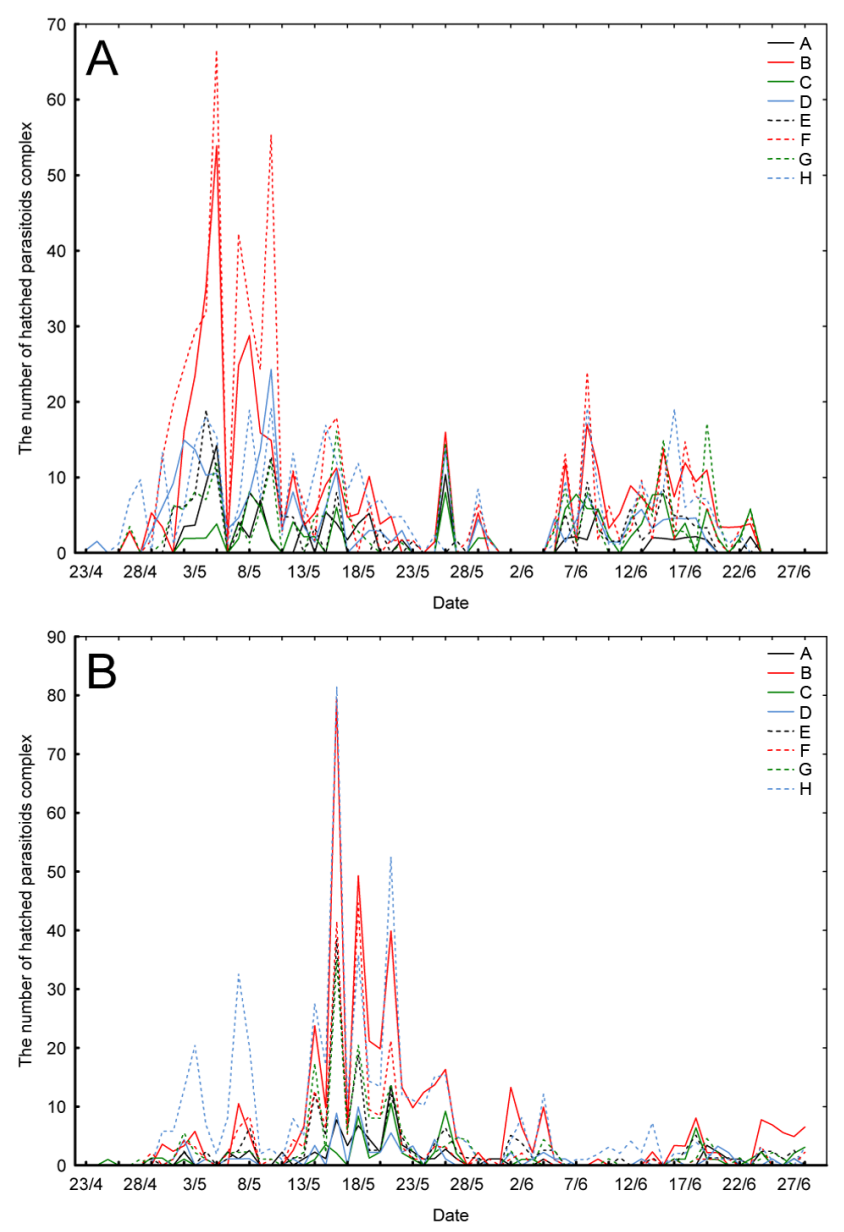

Fig. 7. Dynamics of the spring emergence of the parasitoids (mean daily number hatched) in 2013 (A) and 2014 (B) per 1000 grams of dry leaves collected at each of the sites $(A-H)$.

bouring sites and thus accords with the results of spatial analysis of the leaf damage data.

\section{DISCUSSION}

\section{Population density of the first generation of C. ohridella}

The horse chestnut leaf miner was first recorded in the Czech Republic in 1993. Since that time it has seriously damaged the leaves of horse chestnut trees (Liška, 1997). Study by Volter et al. (2011) reports a high variability in the infestation levels recorded in six cities, ranging from 2 to $62.5 \%$. Changes over the course of five years are also reported. The results of the present study indicate that leaf damage caused by $C$. ohridella was not similar throughout České Budějovice, but ranged between $4 \%$ and $31 \%$ and was associated with both site and year, indicating a significant spatio-temporal variability. High spatial variability and/or within- and between-year fluctuations in infestation levels is also reported for cities in Switzerland (Gilbert et al., 2003; Girardoz et al., 2007a, b), Belgium (Gilbert et al., 2003) and Poland (Baraniak et al., 2005).

The highest damage in both years was recorded at "Nádražní Street" where leaf litter is not removed each winter. Gilbert et al. (2003) and Baraniak et al. (2005) report that the level of infestation by $C$. ohridella is correlat-
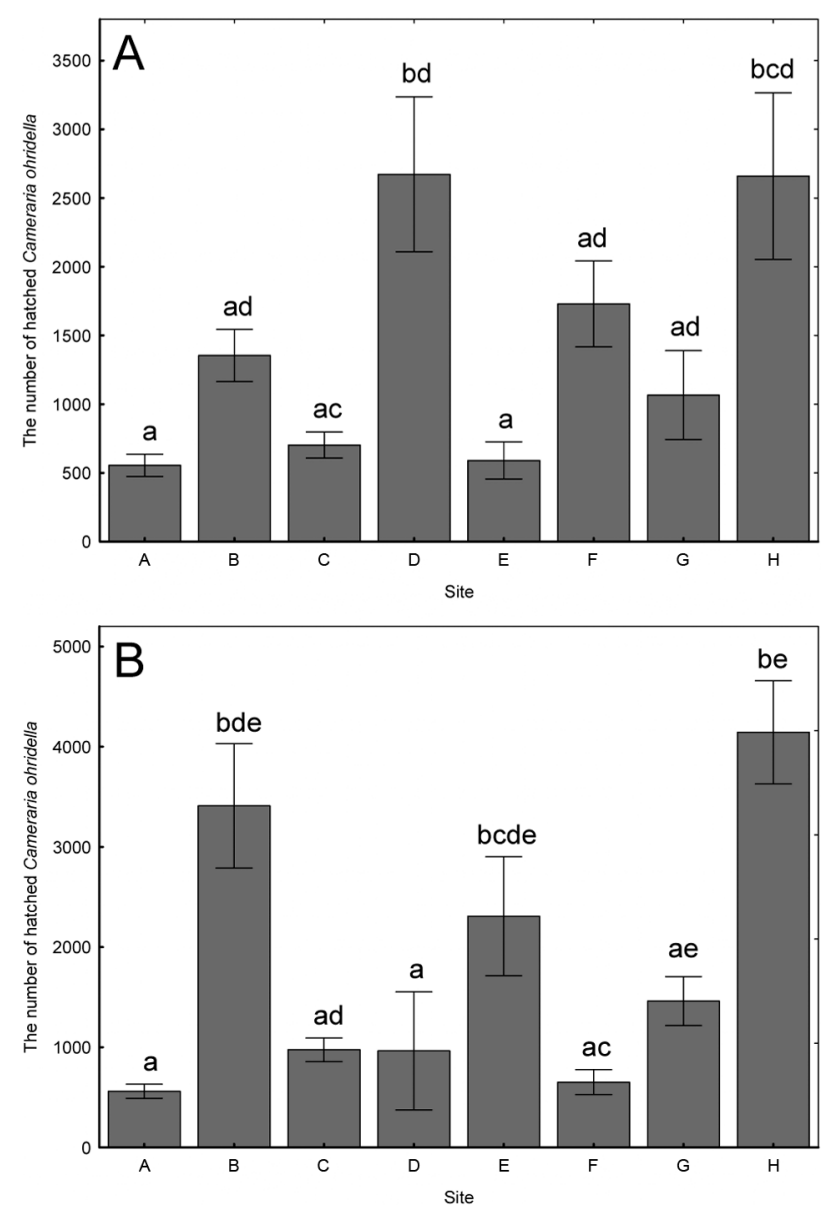

Fig. 8. Total numbers of adults of Cameraria ohridella (mean \pm SEM, $n=5$ ) that emerged in $2013(A)$ and $2014(B)$ per 1000 grams of dry leaves collected at each of the sites. Different letters above bars indicate significant differences (Tukey's test; $p<0.05$ ).

ed with the amount of leaves recorded at a site overwinter. Maintenance of green public areas thus has a significant effect on the horse chestnut leaf miner and the only effective way to regulate the damage caused by $C$. ohridella in spring is raking and removing leaf litter in autumn or early spring (Kehrli \& Bacher, 2003). Leaf removal should be complete because moth populations are able to rebound from a low number of surviving individuals and where it is not feasible to remove $100 \%$ of the leaves, other control measures should be applied (Gilbert et al., 2003). This is even more important for trees growing in streets as infestation may have a higher effect on their health because of their low vigour related to soil compaction and the impermeability of the surface of the substrate under these trees to water and nutrients (Speight et al., 1998) and high levels of pollution. Indeed, "Nádražní Street" is a narrow green belt between a busy road and railway line. The proximity to a busy road and railway line is likely to result in a high concentration of heavy metals in the horse chestnut tree (Aksoy \& Ugur, 1999; Yilmaz et al., 2006). This may weaken the tree making it less resistant to C. ohridella although no direct effect of the concentration of heavy metals on the abundance of other leaf-mining larvae has been confirmed (Mulder \& Breure, 2006). Combination of negative abiotic factors and damage inflicted by $C$. ohridella can 

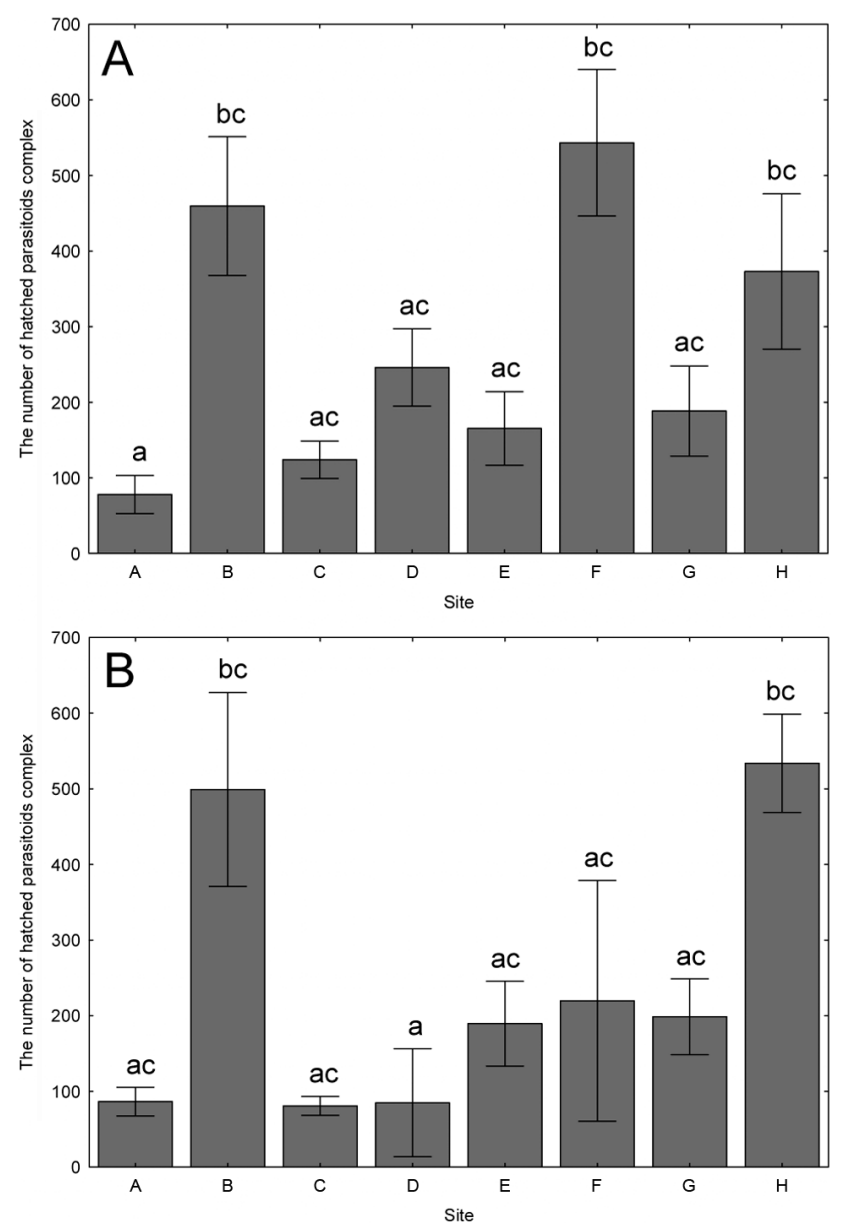

Fig. 9. Total number of adults of the parasitoids complex (mean \pm SEM, $n=5$ ) that emerged in $2013(A)$ and 2014 (B) per 1000 grams of dry leaves collected at each of the sites. Different letters above bars indicate significant differences (Tukey's test; $p<0.05$ ).

escalate the effect of infestation on premature leaf shedding (Freise \& Heitland, 2001) as is reported occurring in "Nádražní Street" in previous years (Kopačka et al., 2011).

The city centre, where the majority of horse chestnut trees are located, is the most intensively maintained and therefore the extent of the damage to horse chestnut leaves should be the least (Kehrli \& Bacher, 2003; Pavan et al., 2003). However, this prediction does not take into consideration outbreaks of horse chestnut leaf miner occurring close by (Baraniak et al., 2005). Spatial analysis based on Moran's index describes the degree of spatial autocorrelation among sites (Chen, 2013). The Moran's index we recorded indicates that the distribution of $C$. ohridella is random, i.e. density of $C$. ohridella at a site is not associated with the density at neighbouring sites. Similar findings are reported by Baraniak et al. $(2004,2005)$ who found a positive correlation of the distance between localities with the degree of infestation of trees only in a small town and only during the third generation of $C$. ohridella larvae. These authors conclude that the presence of refuges in the city outskirts, where there was no raking and removal of leaves, did not seem to have a significant effect on the degree of horse chestnut tree infestation in the centre. In contrast, the results of Gilbert et al. (2003) indicate a strong spatial dependence of infestation levels at up to about 1 and 2

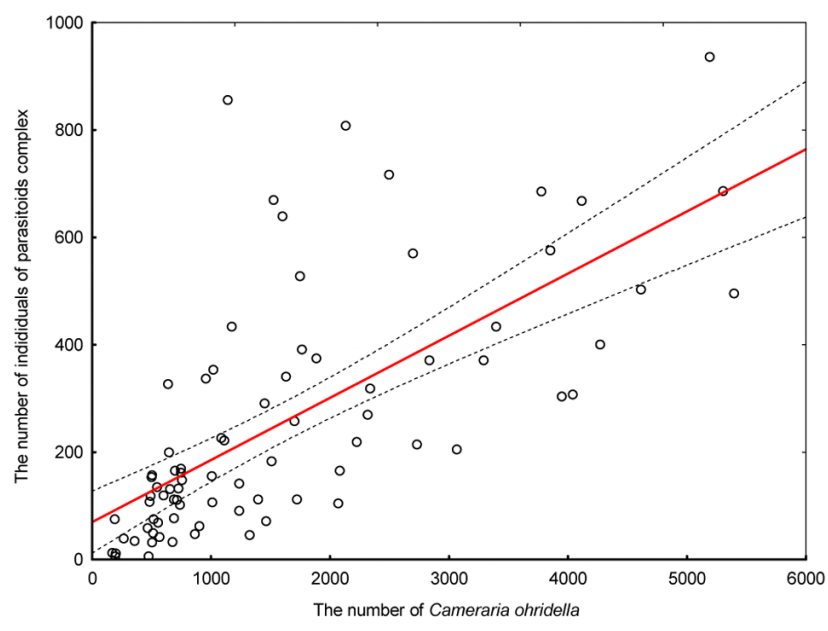

Fig. 10. The relationship between the total numbers of adult parasitoids and adults of Cameraria ohridella that emerged in spring per 1000 grams of dry leaves collected at each of the sites.

$\mathrm{km}$ in Bern and Brussels, respectively. According to these authors the pattern of infestation levels as a function of distance to potential population reservoirs indicates that $C$. ohridella re-invades areas where overwintering leaves are removed from refuge areas such as parks or urban forests. The discrepancy between the above results could be attributed to different geographical locations, different methods and also the different statistical analysis used. Moreover, many factors related to the city's characteristics may play a role, such as the spatial distribution of population reservoirs, topography, prevailing wind direction, or the structure of the streets and buildings in contributing to a canyon effect (Gilbert et al., 2003).

\section{Mortality of diapausing pupae of C. ohridella recorded in autumn}

Leaf samples for estimating pupal mortality were collected at the beginning of leaf fall, as in the study by Girardoz et al. (2007b). Our results revealed that mortality of diapausing pupae at the end of vegetative season was significantly associated with the site. Differences among sites could be due to the leaf senescence and intraspecific competition in the last generation (Girardoz et al., 2007b). The latter factor is, however, not obvious in our data as, for example, in 2013 the highest mortality was recorded in the city centre where the density of $C$. ohridella was the lowest. The overall mortality slightly decreased in 2013 compared to 2012 but the difference was not statistically significant.

\section{Emergence of C. ohridella and its parasitoids from leaf litter after overwintering}

The temperatures inside of photo-eclectors were similar to the air temperatures recorded outdoors as the metal cylinders of the photo-eclectors do not provide any thermal insulation. Thus the system used can be considered to mimic closely natural conditions. The period when the adults start emerging from pupae of $C$. ohridella coincides with the flowering of horse chestnut trees, which occurs between mid-April and mid-May. The emergence occurs at approximately the same time in Central Europe (Kehrli \& 
Bacher, 2003; Kukula-Mlynarczyk \& Hurej, 2007) every year and was also confirmed by the results for adult emergence obtained using photo-eclectors in the present study. There was a two-week delay in peak moth emergence in 2014 compared to 2013, which was most likely due to differences in temperature during winter and early spring. The results also revealed that parasitoids started to emerge from fallen leaves earlier than horse chestnut leaf-miner, which is well documented by many authors (Hellrigl, 2003; Grabenweger, 2004; Grabenweger et al., 2007). Poor synchronization between parasitoid emergence and $C$. ohridella development is believed to be the reason for the lack of control of this species in the first generation (Grabenweger, 2004), but does not significantly affect the abundance of the most important parasitoid in the complex, Minotetrastichus frontalis, and consequently has no effect on the parasitism of C. ohridella (Grabenweger et al., 2007).

The results further revealed that numbers of $C$. ohridella and its parasitoids in senescent leaves were strongly associated with the site from which the sample came and the year. Interaction between site and year was also significant. The relationship between the total number of individuals of the parasitoids complex that emerged and the total number of adults of $C$. ohridella that emerged in spring indicates that the abundance of parasitoids is correlated with that of C. ohridella. This result confirms the conclusions of a recent study in which the authors quantified the numbers and species richness of chalcid wasps (Hymenoptera: Chalcididae) and numbers of $C$. ohridella that emerged from horse chestnut leaf litter samples collected from 35 sites in the Czech Republic (Nováková et al., 2016).

Spatial analysis of the numbers of $C$. ohridella adults and hymenopteran parasitoids that emerged from leaf samples in spring revealed that the distribution of both the pest and its natural enemies in leaf litter is unlikely to be affected by pest and parasitoids density at neighbouring sites, which accords with the finding of the spatial analysis of leaf damage. Some emigration of $C$. ohridella from a site to neighbouring sites is more likely to occur at the end of the vegetative season when suitable environments for caterpillar development are scarce, i.e. when there is less space and food quality is low, which causes $C$. ohridella moths to migrate (Samek, 2003).

Our results further show that the number of adults of parasitoids that emerged are positively correlated with the number of $C$. ohridella that hatched. This indicates that sites with a high density of $C$. ohridella (e.g. those from which no or few leaves were removed) can be considered to be a good source of parasitoids. This is also reported by other authors (Kehrli et al., 2005).

The number of adults of $C$. ohridella that emerged in spring is also positively correlated with damage inflicted by the first generation of $C$. ohridella the previous year. This indicates a persistent and long-standing problem at individual sites. This finding is supported by many other studies (Kehrli \& Bacher, 2003; Baraniak et al., 2004, 2005).

\section{CONCLUSIONS}

Based on our results we conclude that:

(1) The leaf damage caused by the first generation of horse chestnut leaf-miner is site and year dependent. In sites where leaf litter is not removed up to one third of the leaf area can be destroyed.

(2) The mortality of $C$. ohridella pupae recorded before hibernation is closely associated with the site.

(3) The results confirmed previous findings that parasitoids emerge from leaves in spring before $C$. ohridella and their number is positively correlated with the number of $C$. ohridella. The number of moths that emerge the following spring is closely associated with the level of leaf damage caused by the first generation of $C$. ohridella.

(4) There is no spatial correlation between leaf damage and the numbers of $C$. ohridella moths and parasitoid adults that emerged at the sites studied.

ACKNOWLEDGEMENTS. We thank J. Boháč for his valuable advice during this study. J. Jabůrková is thanked for her technical assistance. Also appreciated are the helpful comments and suggestions for improvement of the original version of this article by three anonymous referees. This research received institutional support RVO:60077344. The publication was supported by projects No. 8G15006 from Ministry of Education, Youth and Sports of the Czech Republic and No. 063/2013/Z from the Grant Agency of the University of South Bohemia in České Budějovice.

\section{REFERENCES}

Aksoy A. \& Ugur S. 1999: Elaeagnus angustifolia L. as a biomonitor of heavy metal pollution. - Turk. J. Bot. 23: 83-87.

Baraniak E. Walczak U., Tryjanowski P. \& Zduniak P. 2004: Effect of distance between host trees and leaf litter removal on population density of Cameraria ohridella Deschka \& Dimic, 1986 (Lepidoptera, Gracillariidae) - pest of chestnut (Aesculus sp.) trees. - Pol. J. Ecol. 52: 537-542.

BaraniaK E., WalczaK U. \& ZdUniaK P. 2005: Appearance and migration of the horse-chestnut leafminer Cameraria ohridella in relation to city size and leaf-raking, using the example of two cities in western Poland. - J. Pest Sci. 78: 145-149.

Cebeci H. \& Acer S. 2007: The occurrence of some lepidopterous species on the horse chestnut (Aesculus hippocastanum L.) at Istanbul-Belgrad forest in Turkey. - Acta Agric. Slov. 19: $95-102$.

Cebeci H.H., Grabenweger G. \& Hamit A. 2011: Eulophid parasitoids (Hymenoptera: Eulophidae) of the horse chestnut leafminer, Cameraria ohridella (Lepidoptera: Gracillariidae), from Istanbul, Turkey. - Turk. J. Zool. 35: 777-780.

CHEN Y. 2013: New approaches for calculating moran's index of spatial autocorrelation. - PLOS ONE 8(7): e68336, 14 pp.

Deschka G. \& Dimic N. 1986: Cameraria ohridella sp. n. (Lepidoptera, Lithocolletidae) aus Mazedonien. - Acta Entomol. Jugosl. 22: 11-23.

Doležal P., Sehnal F., Vrba S. \& Zemek R. 2012: Vorrichtung für Extraction von Insekten, besonders aus organischen Substanzen. Gebrauchsmuster Nr. 202012103220.1. Deutshes Patent- und Markenamt.

Ferracini C., Curir P., Dolci M., Lanzotti V. \& Alma A. 2010: Aesculus pavia foliar saponins: Defensive role against the leafminer Cameraria ohridella. — Pest Manag. Sci. 66: 767772. 
Freise J.F. \& Heitland W. 2001: Neue Aspekte zur Biologie und Ökologie der Roßkastanien-Miniermotte, Cameraria ohridella Deschka \& Dimic (1986) (Lep. Gracillariidae), einem neuartigen Schädling an Aesculus hippocastanum. - Mitt Dtsch. Ges. Allg. Angew. Entomol. 13: 135-139.

Gilbert M. \& Gregorre J.C. 2003: Visual, semi-quantitative assessments allow accurate estimates of leafminer population densities: an example comparing image processing and visual evaluation of damage by the horse chestnut leafminer Cameraria ohridella (Lep., Gracillariidae). - J. Appl. Entomol. 127: 354-359.

Gilbert M., Svatoš A., Lehmann M. \& Bacher S. 2003: Spatial patterns and infestation processes in the horse chestnut leafminer Cameraria ohridella: a tale of two cities. - Entomol. Exp. Appl. 107: 25-37.

Girardoz S., Tomov R., Eschen R., Quicke D.L.J. \& Kenis M. 2007a: Two methods of assessing the mortality factors affecting the larvae and pupae of Cameraria ohridella in the leaves of Aesculus hippocastanum in Switzerland and Bulgaria. Bull. Entomol. Res. 97: 445-453.

Girardoz S., Quicke D.L.J. \& Kenis M. 2007b: Factors favouring the development and maintenance of outbreaks in an invasive leaf miner Cameraria ohridella (Lepidoptera: Gracillariidae): a life table study. - Agr. Forest Entomol. 9: 141-158.

Grabenweger G. 2003: Parasitism of different larval stages of Cameraria ohridella. - BioControl 48: 671-684.

Grabenweger G. 2004: Poor control of the horse chestnut leafminer, Cameraria ohridella (Lepidoptera: Gracillariidae), by native European parasitoids: a synchronisation problem. Eur. J. Entomol. 101: 189-192.

Grabenweger G. \& Grill R. 2000: On the place of origin of Cameraria ohridella Deschka \& Dimic (Lepidoptera: Gracillariidae). - Beitr. Entomofaun. 1: 9-17.

Grabenweger G., Hopp H., Jackel B., Balder H., Koch T. \& SCHMOLLING S. 2007: Impact of poor host-parasitoid synchronisation on the parasitism of Cameraria ohridella (Lepidoptera: Gracillariidae). - Eur. J. Entomol. 104: 153-158.

Grodner J., Jablonski T., Kolk A., Przybysz E. \& Slusarski S. 2008: Possibilities to monitoring/control of the horse-chestnut leafminer (Cameraria ohridella) with some acetal derivatives of (8E,10Z)-tetradeca-8,10-dienal. - Pesticides 3-4: 5-13.

Guichard S. \& Augustin S. 2002: Acute spread in France of an invasive pest, the horse chestnut leafminer Cameraria ohridella Deschka \& Dimic (Lep., Gracillariidae). — J. Pest Sci. 75: $145-149$

Hellrigl K. 2003: Cameraria Ohridella: A Che Punto Siamo Arrivati? In: Proceedings of the Symposium on Important Horse Chestnut Pests and Pathogens. University of Bologna, Bologna, pp. 63-68.

JuRA S. 2001: [Estimating the age of trees.] Silva Bohem. 1: 19-20 [in Slovak].

KeHRLi P. \& BACHER S. 2003: Date of leaf litter removal to prevent emergence of Cameraria ohridella in the following spring. Entomol. Exp. Appl. 107: 159-162.

KeHrLI P. \& BACHeR S. 2004: How to safely compost Cameraria ohridella-infested horse chestnut leaf litter on private compost heaps. - J. Appl. Entomol. 128: 707-709.

Kehrli P., Lehmann M. \& Bacher S. 2005: Mass-emergence devices: a biocontrol technique for conservation and augmentation of parasitoids. - Biol. Contr. 32: 191-199.

Kindl J., Kalinová B., Svatoš A., Freise J., Heitland W., Augustin S., Guichard S. \& Avtzis N. 2002: Monitoring the population dynamics of the horse chestnut leafminer Camera- ria ohridella with a synthetic pheromone in Europe. - Plant Protect. Sci. 38: 131-138.

Kobza M., Juhasova G., Adamcikova K. \& Onruskova E. 2011: Tree injection in the management of horse-chestnut leaf miner. Cameraria ohridella (Lepidoptera: Gracillariidae). - Gesunde Pflanz. 62: 139-143.

Kорас̌Ka M. 2011: Composting Leaves of Horse Chestnut Infested by Cameraria ohridella as a Technology for Ecological Regulation of Insect Pest. MSc. Theses, University of South Bohemia, České Budějovice, 85 pp. [in Czech, English abstr.].

KopaČ́a M., Zemek R. \& KopaČKa D. 2011: Good maintanance of city parks contributes to the control of horse chestnut leafminer. - Zahradnictví 10: 53-54 [in Czech, English abstr.].

Kukula-Mlynarczyk A. \& Hurej M. 2007: Incidence, harmfulness and some elements of the horse chestnut leafminer (Cameraria ohridella Deschka \& Dimic) control on white horse chestnut (Aesculus hippocastanum L.). - J. Plant Protect. Res. 47: 53-64.

KuldovÁ J., HrdÝ I. \& JANŠTA P. 2015: The horse chestnut leafminer Cameraria ohridella: Chemical control and notes on parasitisation. - Plant Protect. Sci. 43: 47-56.

LıšKA J. 1997: Verbreitung der Roßkastanienminiermotte in Tschechien. Bundesforschungszentrum für Wald, Forstschutz-Aktuell 21. URL: http://bfw.ac.at/inst4/fs-aktuell/nr21/liska.html.

Měsić A., Barčić J., Barčić J.I., Miličević T., DuraliJa B. \& ČULJAK T.G. 2008: A low environmental impact method to control horse chestnut leaf miner Cameraria ohridella (Deschka \& Dimic). - J. Food Agric. Environ. 6: 421-427.

Mulder C. \& Breure A.M. 2006: Impact of heavy metal pollution on plants and leaf-miners. - Environ. Chem. Letters 4: $83-86$.

Nardini A., Raimondo F., Scimone M. \& Salleo S. 2004: Impact of the leaf miner Cameraria ohridella on whole-plant photosynthetic productivity of Aesculus hippocastanum: insights from a model. - Trees 18: 714-721.

Newcombe R.G. 1998: Two-sided confidence intervals for the single proportion: Comparison of seven methods. - Stat. Med. 17: 857-872.

Nováková P., Holuša J. \& Horák J. 2016: The role of geography and host abundance in the distribution of parasitoids of an alien pest. - Peer J. 4: 1592.

Pavan F., Barro P., Bernardinelli I., Gambon N. \& ZandigiaСОмо P. 2003: Cultural control of Cameraria ohridella on horsechestnut in urban areas by removing fallen leaves in autumn. - J. Arboricult. 29: 253-258.

Péré C., Augustin S., Turlings T. \& Kenis M. 2010: The invasive alien leaf miner Cameraria ohridella and the native tree Acer pseudoplatanus: A fatal attraction? - Agr. Forest Entomol. 12: 151-159.

Perju T., Oltean I., Porca M.M. \& Oprean I. 2004: New aspects concerning the integrated control of the horse chestnut leafmines, Cameraria ohridella Deschka-Dimic. - Bull. Univ. Agric. Sci. Vet. Med. 60: 132-137.

Prenerová E., Zemek R., Weyda F. \& Volter L. 2009: Entomopathogenic fungi isolated from soil in the vicinity of Cameraria ohridella infested horse chestnut trees. - IOBC/WPRS Bull. 45: 321-324.

Prenerová E., Zemek R., Volter L. \& Weyda F. 2013: Strain of entomopathogenic fungus Isaria fumosorosea CCM 8367 (CCEFO.011.PFR) and the method for controlling insect and mite pests. US Patent No. 08574566, issued November 5, 2013.

PuChBerger K.M. 1995: Zur Geschichte der ersten Ausbreitung von Cameraria ohridella Deschka \& Dimic 1986 in Österreich (Lepidoptera, Gracillariidae). - Entomol. Nachrichtenbl. 1: $2-3$. 
Richter D., Sermann H., Jackel B. \& Buttner C.B. 2007a: Pathogenicity of entomopathogenic fungi on hibernating pupae of Cameraria ohridella Deschka \& Dimic 1986 (Lepidoptera, Gracillariidae). Part 1: Pathogenicity against the naked pupa. - Commun. Agric. Appl. Biol. Sci. 72: 399-410.

Richter D., Sermann H., Jackel B. \& Buttner C.B. 2007b: Pathogenicity of entomopathogenic fungi on hibernating pupae of Cameraria ohridella Deschka \& Dimic 1986 (Lepidoptera, Gracillariidae). Part 2: Efficacy of entomopathogenic fungi against pupa in her pupal cell. - Commun. Agric Appl. Biol. Sci. 72: 411-421.

Salleo S., Nardini A., Raimondo F., Lo Gullo M.A., Pace F. \& Giacomich P. 2003: Effects of defoliation caused by the leafminer Cameraria ohridella on wood production and efficiency in Aesculus hippocastanum growing in north-eastern Italy. - Trees 17: 367-375.

SAMEK T. 2003: Diapause of Cameraria ohridella Deschka et Dimic and its impact on the species population dynamics. - J. Forest Sci. 49: 252-258.

SAMEK T., NovotnÝ D. \& JANKovskÝ L. 2006: Infection of wintering pupae of horse-chestnut leafminer Cameraria ohridella Deschka et Dimić by Verticillium lecanii (Zimmerman) Viégas. - J. Forest Sci. 52: 136-140.

Santi F., Accinelli G. \& Maini S. 2000: Cameraria ohridella, minatore fogliare dell'ippocastno: catture con trappole sessuali e note di biologia. - Inform. Fitopatol. 11: 7-11.

Schemmer R., Chládeková P., Medo J. \& Barta M. 2016: Natural prevalence of entomopathogenic fungi in hibernating pupae of Cameraria ohridella (Lepidoptera: Gracillariidae) and virulence of selected isolates. - Plant Prot. Sci. 52: 199-208.

Siegel S. \& Castellan N.J.J. 1988: Nonparametric Statistics for the Behavioral Sciences. McGraw-Hill, New York, 399 pp.

SKUHRAVÝ V. 1999: An overview of knowledge about the horse chestnut miner Cameraria ohridella Desch. \& Dim. (Lep., Gracillariidae). — J. Pest Sci. 72: 95-99.

Speight M.R., Hails R.S., Gilbert M. \& Foggo A. 1998: A horse chestnut scale (Pulvinaria regalis) (Homoptera: Coccidae) and urban host tree environment. - Ecology 79: 10503-1513.

Sokal R.R. \& RohlF F.J. 1969: Biometry. Freeman, San Francisco, $937 \mathrm{pp}$.

Sukovata L., Czokajlo D., Kolk A., Slusarski S. \& Jablonski T. 2011: An attempt to control Cameraria ohridella using an attract-and-kill technique. - J. Pest Sci. 84: 207-212.

Svatoš A., Kalinová B., HošKovec M., Kindl J., Hovorka O. \& HRDÝ I. 1999: Identification of a new lepidopteran sex pheromone in picogram quantities using an antennal biodetector: (8E,10Z)-tetradeca-8,10-dienal from Cameraria ohridella. Tetrahedron Lett. 40: 7011-7014.
Svatoš A., Kalinová B. \& HrdÝ I. 2009: Cameraria ohridella: 10 years of sex pheromone and kairomone research. - J. Appl. Entomol. 133: 319-327.

Thalmann C., Freise J., Heitland W. \& Bacher S. 2003: Effects of defoliation by horse chestnut leafminer (Cameraria ohridella) on reproduction in Aesculus hippocastanum. - Trees 17: 383-388.

Valade R., Kenis M., Hernandez-Lopez A., Augustin S., Mena N.M., Magnoux E., Rougerie R., Lakatos F., Roques A. \& LoPeZ-VAAMONDE C. 2009: Mitochondrial and microsatellite DNA markers reveal a balkan origin for the highly invasive horse-chestnut leaf miner Cameraria ohridella (Lepidoptera, Gracillariidae). - Mol. Ecol. 18: 3458-3470.

Volter L. \& Kenis M. 2006: Parasitoid complex and parasitism rates of the horse chestnut leafminer, Cameraria ohridella (Lepidoptera: Gracillariidae) in the Czech Republic, Slovakia and Slovenia. - Eur. J. Entomol. 103: 365-370.

Volter L., Zemek R., Weyda F. \& Prenerová E. 2011: Infestation of horse chestnut trees by the horse chestnut leafminer ( $\mathrm{Cam}$ eraria ohridella) in the Czech Republic. - Rostlinolékař 3: 17-18 [in Czech, English abstr.].

Weyda F., Pflegerová J., StašKová T., TomČala A., Prenerová E., Zemek R., Volter L. \& Kodrík D. 2015: Ultrastructural and biochemical comparison of summer active and summer diapausing pupae of the horse chestnut leaf miner, Cameraria ohridella (Lepidoptera: Gracillariidae). - Eur. J. Entomol. 112: 197-203.

Yilmaz R., Sakcali S., Yarci C., Aksoy A. \& Ozturk M. 2006: Use of Aesculus hippocastanum L. as a biomonitor of heavy metal pollution. - Pak. J. Bot. 38: 1519-1527.

ZAR J.H. 1999: Biostatistical Analysis. Prentice Hall, New Jersey, $663 \mathrm{pp}$.

Zemek R., Prenerová E., Volter L., Weyda F. \& Skuhravý V. 2006: Perspectives for the biological control of Cameraria ohridella. - Comm. Agr. Appl. Biol. Sci. 72: 521-526.

Zemek R., Prenerová E. \& Weyda F. 2007: The first record of entomopathogenic fungus Paecilomyces fumosoroseus (Deuteromycota: Hyphomycetes) on the hibernating pupae of Cameraria ohridella (Lepidoptera: Gracillariidae). — Entomol. Res. 37: 135-136.

Zemek R., Prenerová E., Awad M. \& Hussein H.M. 2012: Potential of the strain of entomopathogenic fungus Isaria fumosorosea CCM 8367 as a biological control agent against Cameraria ohridella and other pests. - Acta Fytotech. Zootech. 15: 79-80.

Received May 18, 2016; revised and accepted December 23, 2016 Published online January 24, 2017 